\title{
Endoscopic removal of a metallic touchpad stylus with partially collapsible body from the duodenojejunal flexure in a young boy
}

\author{
Ramnik V Patel, ${ }^{1}$ Dhaval Govani, ${ }^{2}$ Juliette King King, ${ }^{1}$ Oliver Gee ${ }^{1}$
}

1 Department of Paediatric Surgery, Birmingham Children's Hospital NHS Foundation Trust Birmingham, UK

${ }^{2}$ Department of Medical Student, Birmingham Medical School, Birmingham, UK

\section{Correspondence to}

Ramnik V Patel,

ramnik@doctors.org.uk

Accepted 28 September 2014

\section{DESCRIPTION}

An 11-year-old boy was playing with a stylus in his mouth and accidentally swallowed it. He developed left-sided abdominal pain with tenderness in the umbilical area. A radiograph of the stylus was taken (figure 1A). The initial radiograph showed the stylus lying horizontally in the abdomen well below the stomach (figure 1B). A radiograph taken the next day showed that it had shifted slightly to the left (figure 1C). The subsequent radiograph taken on the third day showed the stylus had moved to the midline and was above the colonic gas shadow (figure 1D). The patient's abdominal pain become intermittent and mild, so he underwent abdominal radiograph after 8 days; the stylus was still in the same place below the stomach and above the colonic gas shadows (figure $1 \mathrm{E}$ ). He was pain free and a repeat abdominal radiograph on day 11 showed the stylus still in the same position (figure $1 \mathrm{~F}$ ). Under fluoroscopy, the stylus appeared vertical and contrast showed it to be at the duodenojejunal flexure (figure 1G). The patient underwent upper gastrointestinal endoscopy during which the stylus was seen lying vertically at the fourth part and the tip was over the aorta in the third part of the duodenum. We were able to snare and rotate the stylus, moving it through to the pylorus where the snare was repositioned in the stomach enabling the object to be delivered through the gastro-oesophageal junction and pharynx. The removed stylus showed a partially collapsible body of over $10 \mathrm{~cm}$ (figure $1 \mathrm{H}$ ). A foreign body at the duodenojejunal flexure with its tip over the aorta is a potentially lethal emergency and involves advanced endoscopy skills for retrieval. ${ }^{1-3}$
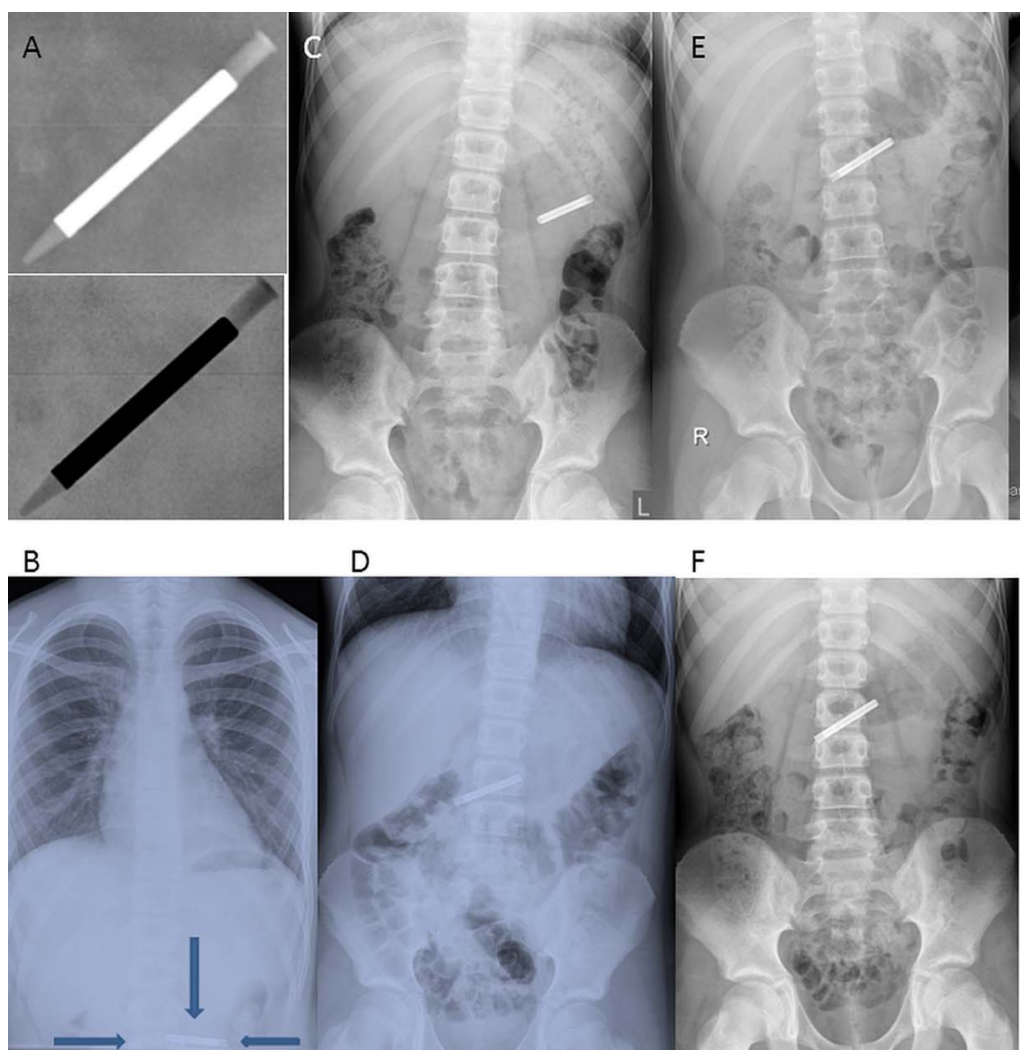

D

F

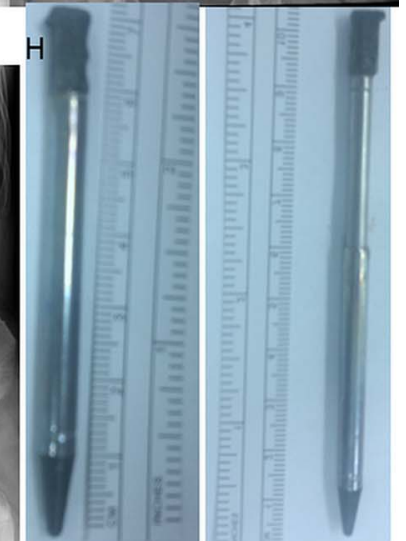

Figure 1 Sequential imaging of (A) radiograph of the stylus; $(B)$ initial radiograph: note horizontal stylus at the bottom (arrows); (C) 24 hour radiograph with stylus on left upper abdomen; (D) 72 hour radiograph with stylus above and outside the colonic gas shadow; $(E)$ radiograph at 1 week: stylus outside the stomach and colonic gas shadows; (F) radiograph at 10 days showing static stylus; (G) upper gastrointestinal contrast study showing stylus at duodenojejunal flexure; $(\mathrm{H})$ retrieved stylus: collapsed over $7 \mathrm{~cm}$ in length and expanded over $10 \mathrm{~cm}$ in length. 


\section{Learning points}

- Most ingested foreign bodies that reach the stomach pass spontaneously through the gut (80-90\%); however, there should be a low threshold of intervention especially for long, sharp objects that remain in the same position for over a week, and for those objects having the potential to unfold or open up, particularly when located in the duodenojejunal flexure area, even if the patient remains asymptomatic.

- It is historically believed that long objects get arrested at the junction of the second and third part of the duodenum and are unable to negotiate the C loop of the duodenum, but the duodenojejunal flexure seems to be the site of arrest for further progression as the angle at the duodenojejunal flexure can be acute and difficult to negotiate. Normally, long sharp objects take the blunt end forward at the duodenojejunal flexure leaving the sharp end to rest on the abdominal aorta with pulsatile movement and may erode the duodenum and cause fatal haemorrhage, perforation, obstruction, entrapment or migration if not removed in time.

- Foreign body retrieval from beyond the second part of duodenum provides the endoscopist with unique challenges for management and treatment leading to a successful retrieval of an object such as a non-impacted ingested stylus across the $C$ loop of the duodenum and the pylorus, gastro-oesophageal junction and pharyngeal curves via endoscopy using advanced endoscopy skills.
Acknowledgements The authors are grateful to the surgical team at Worcestershire Royal Hospital for advice and referral and Dr Karen Bradshaw, Consultant Paediatric Radiologist and Dr Barry Lambert, Consultant Anaesthetist at Birmingham Children's Hospital for their expert help.

Competing interests None.

Patient consent Obtained.

Provenance and peer review Not commissioned; externally peer reviewed.

\section{REFERENCES}

1 National Electronic Injury Surveillance System Accidents Records. Accidents-pens and pencils-years 1997-2010 — internal. http://www.hospital-data.com/accidents/ 1685-pens-and-pencils/internal/index.html

2 Cho EA, Lee du $\mathrm{H}$, Hong $\mathrm{HJ}$, et al. An unusual case of duodenal perforation caused by a lollipop stick: a case report. Clin Endosc 2014;47:188-91.

3 Islam SR, Islam EA, Hodges $D$, et al. Endoscopic removal of multiple duodenum foreign bodies: an unusual occurrence. World J Gastrointest Endosc 2010;2:186-9.

Copyright 2014 BMJ Publishing Group. All rights reserved. For permission to reuse any of this content visit http://group.bmj.com/group/rights-licensing/permissions.

BMJ Case Report Fellows may re-use this article for personal use and teaching without any further permission.

Become a Fellow of BMJ Case Reports today and you can:

- Submit as many cases as you like

- Enjoy fast sympathetic peer review and rapid publication of accepted articles

- Access all the published articles

- Re-use any of the published material for personal use and teaching without further permission

For information on Institutional Fellowships contact consortiasales@bmjgroup.com

Visit casereports.bmj.com for more articles like this and to become a Fellow 